\title{
Gram-negative bacterial LPS induced poor uterine receptivity and implantation failure in mouse: Alterations in IL-1 $\beta$ expression in the preimplantation embryo and uterine horns
}

\author{
KAUSHIK DEB ${ }^{1}$, MADAN MOHAN CHATURVEDI ${ }^{2}$, \& YOGESH KUMAR JAISWAL ${ }^{1}$ \\ ${ }^{1}$ Molecular Biology $\mathcal{E}$ Reproductive Immunology Laboratory, School of Studies in Biochemistry, Fiwaij University, Gwalior, \\ India, and ${ }^{2}$ Department of Zoology, University of Delhi, Delhi, India
}

\begin{abstract}
Genito-urinary tract or systemic infections of the gram-negative bacteria in pregnant women, causes abortions, preterm labor, and several other perinatal complications. LPS is the most potent antigenic component of the gram-negative bacterial cell wall and is known to modulate the expression of various proinflammatory cytokines. Here we investigate the role of the soluble form of IL-1 i.e., IL- $1 \beta$ in the 'minimum dose' of LPS induced pregnancy loss in mice. Uterine cross-sections on each day of the preimplantation period of pregnancy were examined histopathologically for finding out LPS induced changes in the uterine preparation for embryo implantation. The expression of IL- $1 \beta$ in the various stages of the preimplantation period of pregnancy was studied by RT-PCR in the embryos and the uterine horns of the LPS treated and normal pregnant mice. We found that LPS significantly alters the proliferation of the glandular epithelium, luminal epithelium and stroma during the preimplantation period. We also found large infiltration of macrophages into the uterine horns of the LPS treated animals. The level and pattern of IL-1 $\beta$ expression in the preimplantation embryos and uterine horns were also altered in LPS treated animals. These observations indicate that LPS can alter the uterine preparation for blastocyst implantation, which could be due to the change in the IL- $1 \beta$ expression in the uterine horns. However, a change in the expression pattern of IL-1 $\beta$ in the preimplantation embryos underlines the significance of this molecule in LPS induced pregnancy loss or implantation failure in mouse.
\end{abstract}

Keywords: Lipopolysaccaharides, Interleukin-1, cytokine, blastocyst, mitotic bodies, mcrophages

\section{Introduction}

Many of the reported actions of cytokines are clearly related to combating bacterial infections [1]. During gram-negative bacterial infections bacterial lipids can be easily recognized by the host immune system because they are structurally distinct from mammalian cell lipids. Mononuclear phagocytes express a cell surface receptor that can recognize many such foreign lipids, particularly those derived from the cell walls of gram-negative bacteria, collectively called endotoxin or lipopolysaccharide (LPS) (for a review see [2]). LPS is the most potent antigenic component of the gramnegative bacterial cell wall. Genital tract infection/ vaginitis caused by Gram-negative bacteria is one of the major causes of gynecologic morbidity, such as infertility, ectopic pregnancy, preterm labor and chronic pelvic pain $[3,4]$. Beside this, systemic gram-negative bacterial infections like typhoid fever caused by Salmonella typhi, during pregnancy can cause several perinatal complications and preterm labor. Activated mononuclear phagocytes secrete chemokines and proinflammatory cytokines like IL1, IL-6, TNF etc. that function in the recruitment of blood monocytes and neutrophils to the local site of inflammation. Proinflammatory cytokines like IL1 , TNF etc., are secreted by a wide variety of cells during a pathogenic response. Interleukin-1 was initially discovered as a protein capable of inducing pyrexia (endogenous pyrogens). Thus, most of the proinflammatory cytokines are known as pyroxenes, and the increase in core temperature that they induce may promote the antibacteial activity of leukocytes [5].

Interleukin-1 (IL-1) is an immunoregulatory cytokine with several functions, including stimulation of $\mathrm{T}$ lymphocyte, cytokine production,

Correspondence: Kaushik Deb, Ph.D., 463a, Life Science Center, University of Missouri, Columbia, MO, 65211, USA. Tel: 15738827793.

E-mail: debk@missouri.edu

ISSN 1064-7449 print/ISSN 1098-0997 online (C 2005 Taylor \& Francis

DOI: $10.1080 / 10647440500147885$ 
lympho-cyte proliferation, macrophage activation and initiation of the inflammatory cytokine cascade [6]. The two forms of IL- 1 , IL- $1 \alpha$ and IL- $1 \beta$, have similar biological activities, but are distinct peptides, encoded by separate genes. The molecular weight of both the forms of IL-1 protein is $17 \mathrm{kDa}$., which show $\sim 26 \%$ sequence homology, bind to the same receptor (i.e., IL-1RI) and mediate similar actions. IL- $1 \beta$ is the predominant form of IL- 1 that is produced by most cells and is secreted as a soluble form. IL-1 causes the rapid induction of a wide variety of genes that encode for proinflammatory proteins and cytokines.

Although incompletely defined, it is clear that a number of molecules including growth factors, cytokines, prostaglandins (PGs), histamine, platelet activating factors and various other molecules have been implicated in the process of implantation [7], which, render the uterus receptive and directs the embryo-uterine interactions to initiate the process of implantation [8]. Cytokines produced by the developing embryo and the maternal endometrium include leukemia inhibitory factor [9], interleukin $[10,11]$, hepatocyte growth factor [12], stem cell factor $[13,14]$, macrophage colony stimulating factor [15], insulin like growth factors [16], tumor necrosis factor [17] etc. However, the actual function of these cytokines in implantation is not well understood. The implantation process is described as an inflammatory reaction and it is proposed that there exists a defined pattern and level of expression of these proinflammatory molecules at the feto-maternal interface. Any disturbance in this delicate immune balance can lead to implantation failure or pregnancy loss.

In a previous study we found that a single dose of $5 \mu \mathrm{g} \mathrm{LPS/} \mathrm{animal} \mathrm{(given} \mathrm{i.p.} \mathrm{on} \mathrm{day-} 0.5$ of pregnancy) was the "minimum dose" (MD) required to cause total implantation failure in mice [18]. We have also seen that high levels of LPS induced IL- $1 \alpha$ cause implantation failure in mice [18]. In this study we tried to determine the role of the secreted form of IL-1 i.e., IL-1 $\beta$ in preimplantation embryonic development and LPS induced implantation failure in mice. Since LPS is know to modulate the expression of IL- $1 \alpha$ in preimplantation embryos and uterine horns, leading to implantation failure [18], we were interested to study its effect on the level and pattern of expression of IL- $1 \beta$ too. Histopathological analyses of the uterine cross sections obtained from animals treated with the MD of LPS were carried out to find out its pathogenic effects on the uterine preparation for implantation. Our studies indicate that both the soluble and membrane bound forms of IL-1 are involved in LPS induced implantation failure of the blastocyst in mouse.

\section{Materials and methods}

Animals

Park strain mice (6-7 wks, $20 \mathrm{~g}$ ) were maintained at $25^{\circ} \mathrm{C}$ in our animal house with $12: 12 \mathrm{~h}$ light: dark schedule. They were fed with pelleted diet (Amrut India Pvt. Ltd, New Delhi, India) and water ad libitum. Sexually matured female animals with normal estrus cycles were checked for proestrous and were individually caged overnight with proven fertile males for mating. The females were checked for vaginal plugs on next day morning. Females with positive vaginal plugs were considered as on day half (day 0.5) of pregnancy.

\section{Histopathology}

The histopathological analysis of uterine horns was carried out according to a standard procedure. The small portions of recovered uteri from pregnant animals of each groups were dissected out, freed from fat bodies and fixed in buffered formalin for $24 \mathrm{~h}$. Tissues were dehydrated in graded series of ethanol, cleared in xylene, infiltrated and embedded in paraffin wax at $60^{\circ} \mathrm{C}$. The blocks were sectioned at $8 \mu \mathrm{m}$ using a microtome (Leica, Germany). The tissue sections were stained with Haematoxylin and Eosin solutions, observed under a microscope (Nikon, Japan) using 10X and 40X objectives and photographed.

The cross sections of uterine horns were checked for the presence of mitotic bodies and macrophages. The number of mitotic bodies per 100 nuclei was counted according to Finn et al. (1995) [19]. The distribution of macrophages in uterine sections were quantitated by counting their numbers per $40 \mathrm{X}$ view field under the microscope according to Bagavandoss et al. (1990) [20].

Histopathological analysis of uterine horns at different stages of preimplantation period of pregnancy in animals treated with the 'minimum dose' of LPS on day-0.5 of pregnancy

The present study was conducted to analyze the LPS induced alterations in the uterine horns of pregnant animals during the different stages of preimplantation period of pregnancy. The pregnant females were divided into 5 groups i.e., (Group I, II, III, IV and V) of 6 animals each. Three pregnant animals of each group received single i.p. injection of the 'minimum dose' of LPS on day- 0.5 of pregnancy. The remaining three pregnant animals in each group (i.e., control) received $100 \mu \mathrm{l}$ of sterile normal saline in a similar fashion. All animals of Group I, II, III, IV and $\mathrm{V}$ were killed by cervical dislocation on days 0.5 (after $2 \mathrm{~h}$ of treatment), 1.5, 2.5, 3.5, and 4.5 of 
pregnancy, respectively. The uterine horns were immediately processed as described earlier for histopathological examinations.

\section{Superovulation and embryo recovery at different time points}

The female mice (6-7 wks, $20 \mathrm{~g}$ ) were induced to superovulate with i.p. injections of $5 \mathrm{IU}$ each of PMSG and hCG (Intervet, Holland) at an interval of $48 \mathrm{~h}$. Twenty to 25 superovulated pregnant animals were sacrificed, at each time, by cervical dislocation, at different time points through days 0.5 to 4.5 (days $1.5,2.5,3.5,4.0,4.125,4.25,4.33$, and 4.42) of pregnancy. About 500 embryos/group were recovered, from these animals at each time point/day of pregnancy, by flushing the excised reproductive tracts with sterile PBS. They were immediately frozen and stored at $-70^{\circ} \mathrm{C}$ for isolation of total RNA. The uterine horns of the animals were immediately processed for total RNA isolation.

Effect of LPS on expression of IL-1 $\beta$ in embryos and uterine horns collected at different stages of preimplantation period of pregnancy

Experiments were performed to study the effect of LPS on the expression of IL- $1 \beta$ in embryos and uterus collected at different stages of preimplantation period (i.e., days 1.5, 2.5, 3.5, 4.0, 4.125, 4.25, 4.33, and 4.42) of pregnancy by RT-PCR. Park strain mice (6-7 weeks) were superovulated with PMSG and $\mathrm{hCG}$ as per the protocol mentioned earlier. The 'minimum dose' of LPS (i.e., $5 \mu \mathrm{g} /$ animal) in $100 \mu \mathrm{l}$ of sterile normal saline (determined in previous study) was injected to each pregnant animal through i.p. route on day- 0.5 of pregnancy. The control animals received $100 \mu \mathrm{l}$ of sterile normal saline in a similar manner. The animals of both groups were sacrificed at narrow intervals of the preimplantation period (i.e., days-1.5, 2.5, 3.5, 4.0, 4.125, 4.25, 4.33, and 4.42) of pregnancy to collect the embryos and uterine horns. A total of about 500 embryos were collected at each time to detect the positive mRNA signals for IL- $1 \beta$ by RT-PCR.

Preparation of total cellular RNA from embryos collected at different stages of preimplantation period of pregnancy

A total of 500 preimplantation (2-cell to blastocyst stage) stage embryos were collected after superovulation and resuspended in $200 \mu \mathrm{l}$ of sterile PBS. The collected embryos were directly used for extraction of total cellular RNA using the "High Pure RNA Isolation Kit" (Boehringer Mannheim, Germany). RNA was isolated as per the instructions provided by the manufacturer and was finally eluted in $60 \mu \mathrm{l}$ of elution buffer. $15 \mu \mathrm{l}$ of each extract was used for every reaction of RT-PCR.

Extraction of total cellular RNA from uterine horns collected at different stages of preimplantation period of pregnancy

Total RNA was extracted from uterine horns collected from control and LPS treated pregnant animals by a using the guanidium isothiocyanatephenol chloroform method [21]. The animals were sacrificed by cervical dislocation and uterine horns were removed quickly, washed with chilled normal saline $(0.9 \% \mathrm{NaCl})$, cleaned, blotted dry and weighed. About $100 \mathrm{mg}$ of the tissue was used for total RNA isolation at each time. The concentration of total cellular RNA was estimated at $A_{260}$ (1 $\mathrm{A}_{260}=40 \mu \mathrm{g}$ of RNA) and was stored at $-20^{\circ} \mathrm{C}$ for further studies. The quality of the RNA was checked by agarose gel $(1 \%)$ electrophoresis. Ten micrograms of the extracted RNA was used for each reaction of RT-PCR.

\section{Reverse Transcription-Polymerase Chain Reaction (RT-PCR)}

The reverse transcription polymerase chain reaction (RT-PCR) was carried out using "Titan ${ }^{\mathrm{TM}}$ One tube RT-PCR System" (M/S Boehringer Mannheim, Germany). It was carried out as per the instructions provided by the manufacturer. AMV reverse transcriptase was used in the reaction to synthesize the first strand of DNA and an enzyme blend of Taq DNA polymerase and Pow DNA polymerase was used for second strand synthesis and for subsequent steps of PCR. One micrlitre of the $4 \mathrm{dNTP}$ mix (10 mM each dNTP; MBI Fermentas, Lithuania, final concentration $0.2 \mathrm{mM}$ each $\mathrm{dNTP}$ ) and $1 \mu \mathrm{l}$ each of the upstream and downstream primers (20 $\mu \mathrm{M}$ stock, Clontech USA) and total RNA extract were added to a total reaction volume of $50 \mu \mathrm{l}$. This was overlaid with $50 \mu \mathrm{l}$ of mineral oil.

The upstream and downstream primers for IL- $1 \beta$ were initially purchased from $\mathrm{M} / \mathrm{S}$ Clontech USA, and later synthesized from $\mathrm{M} / \mathrm{S}$ Genset Singapore Biotech Pte. Ltd. Singapore. The primers for $\beta$-actin were synthesized from $\mathrm{M} / \mathrm{S}$ Genset Singapore Biotech Pte. Ltd. Singapore and were used as internal control throughout the experiments [22]. The primers used were: 5'-ATGGCAACTGTTCC TGAACTCA ACT-3' plus 5'-CAGGACAGGTATAGATTCTTTCCTTT-3' for IL-1 $\beta$ and 5'GGGCACAGTGTGGGTGAC-3' plus 5'-CTGGCACCACACCTTCTAAC-3' for $\beta$-actin.

One round of RT was carried out in a thermocycler (MJ Research, USA) equilibrated at $50^{\circ} \mathrm{C}$ for $30 \mathrm{~min}$, which was followed by an initial denatura- 
tion step at $94^{\circ} \mathrm{C}$ for $2 \mathrm{~min}$. This was followed by 35 cycles of PCR. In each cycle of PCR the denaturation was carried out for $1 \mathrm{~min}$ at $94^{\circ} \mathrm{C}$, annealing was carried out for $1 \mathrm{~min}$ at $60^{\circ} \mathrm{C}$ and elongation was carried out for $2 \mathrm{~min}$ at $68^{\circ} \mathrm{C}$ and elongation was carried out for $2 \mathrm{~min}$ at $68^{\circ} \mathrm{C}$. Finally the samples were elongated for $7 \mathrm{~min}$ at $68^{\circ} \mathrm{C}$ and then stored at $4{ }^{\circ} \mathrm{C}$ till further use. The RT-PCR products were confirmed by sequencing.

\section{Results}

Histopathological analysis of uterine horns at different stages of the preimplantation period of pregnancy in animals treated with the 'minimum dose' of LPS on day 0.5 of pregnancy

The pregnant animals were treated with the 'minimum dose' of LPS on day- 0.5 of pregnancy and histopathological alterations that occur in the uterine horns were monitored on different stages of the preimplantation period of pregnancy (i.e., from day0.5 to 4.5 of pregnancy). The changes observed on each day of pregnancy were as follows:

Day-0.5 of pregnancy. The cross sections of uterine horns from LPS treated animals showed hyperplasic and degenerated luminal epithelium with a large number of mitotic figures as compared to that of the control. The glandular epithelium had also undergone hyperplasia. The stroma was highly vascularised with a large number of infiltrating macrophages as compared to that of the control (Figure $1 \mathrm{a}, \mathrm{b}$, and c). However, degeneration of luminal epithelium and hyperplasia in glandular epithelium were not observed in cross sections of uterine horns from control animals. Moreover, few macrophages were observed in stroma of cross sections of uterine horns from control animals (Figure 2a) as compared to the treated animals (Figure $2 b$ ).

A large number of mitotic bodies were found in luminal and glandular epithelium and in stroma of cross sections of uterine horns from control and treated animals. However, no significant difference in the number of mitotic bodies was observed between the control and LPS treated animals.

Day-1.5 of pregnancy. The uterine sections from LPS-treated animals showed highly hyperplasic luminal epithelium with less number of mitotic bodies $(5 \pm 0.31$ per 100 nuclei) as compared to that of the control $(15 \pm 0.948 / 100$ nuclei). These sections also showed degenerating glands with more mitotic bodies in glandular epithelium $(31 \pm 0.316$ per 100 nuclei) as compared to that of the control $(26 \pm 1.87$ per 100 nuclei) (Figure $1 \mathrm{a}, \mathrm{b}$ and $\mathrm{c})$. A large number of scattered macrophages were also
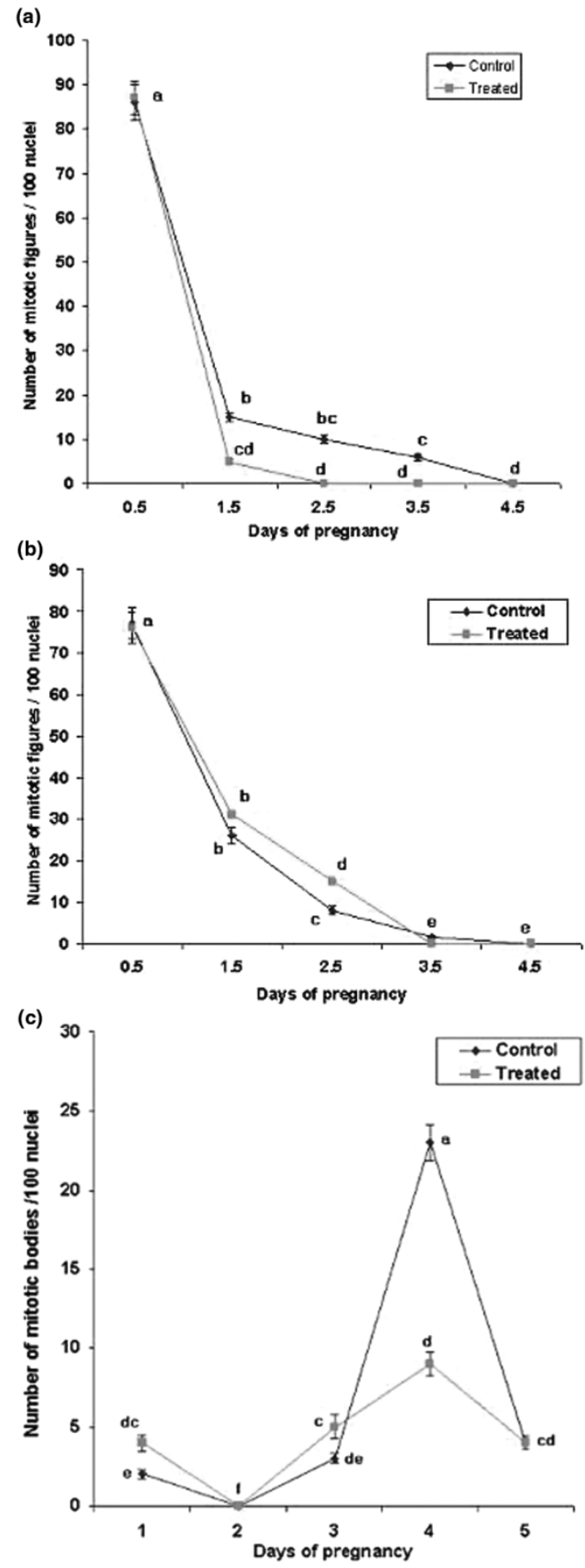

Figure 1. (a) Effect of the 'minimum dose' of LPS on the number of mitotic figures in luminal epithelium of uterus collected from control and LPS treated animals during different stages of preimplantation period of pregnancy. Means bearing similar superscripted alphabets do not differ from each other at $P$ $\leqslant 0.05$. (b) Effect of the 'minimum dose' of LPS on the number of mitotic figures in granular epithelium of uterus collected from control and LPS treated animals during different stages of preimplantation period of pregnancy. Means bearing similar superscripted alphabets do not differ from each other at $P$ $\leqslant 0.05$. (c) Effect of the 'minimum dose' of LPS on the number of mitotic figures in uterine stroma of uterus collected from control and LPS treated animals during different stages of preimplantation period of pregnancy. Means bearing similar superscripted alphabets do not differ from each other at $P \leqslant 0.05$. 

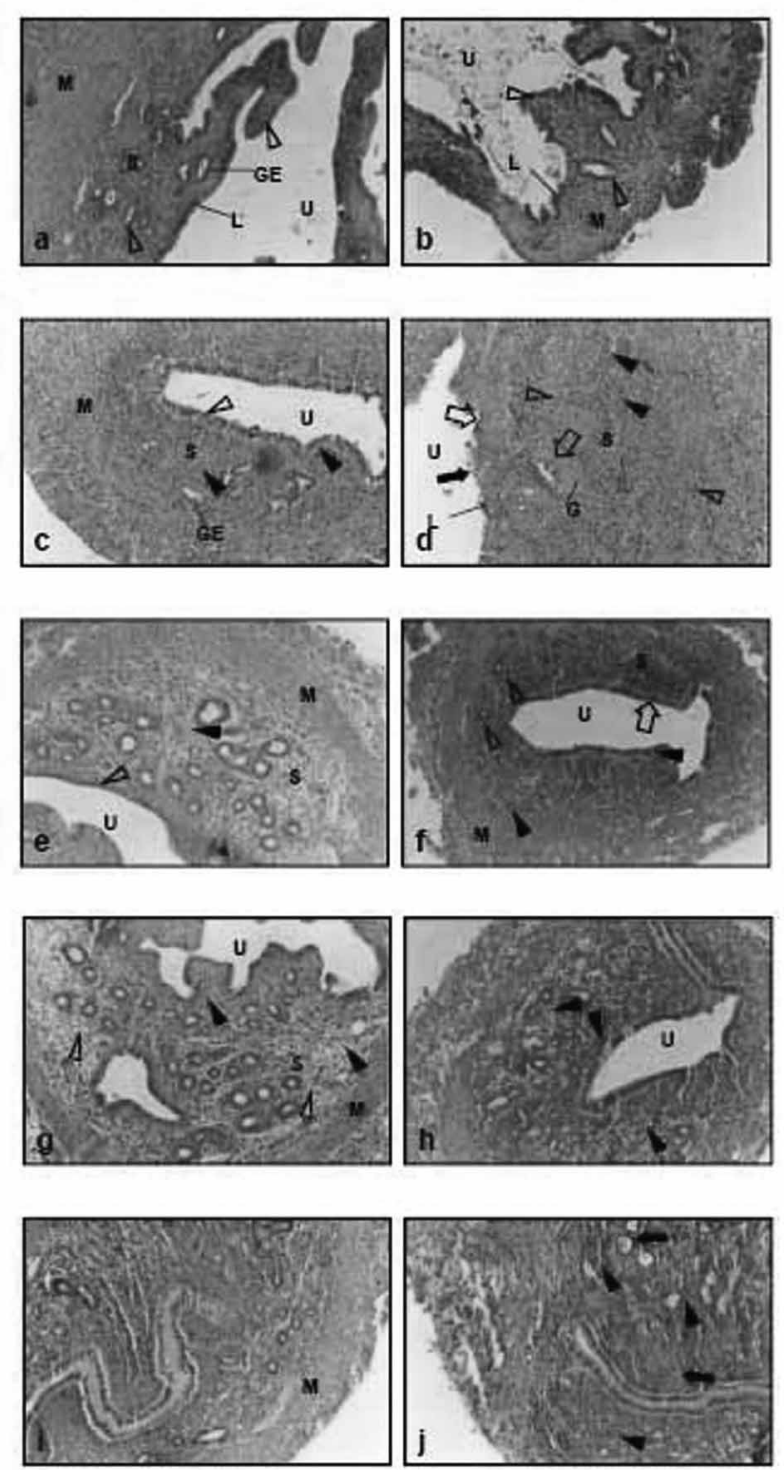

Figure 2. Cross sections of uterine horns from control animals and animals treated with the 'minimum dose' of LPS on day 0.5 of pregnancy. Note macrophages (closed arrow heads), mitotic bodies (open arrow heads), necrosis (closed arrow), hyperplasia (open arrow heads), stroma (S), luminal epithelium (LE), glandular epithelium (GE), myometrium $(\mathrm{M})$ and uterine lumen (UL). Panels (a), (c), (e), (g) and (i) - show cross sections of uterine horns from control animals on days 0.5, 1.5, 2.5, 3.5 and 4.5 of pregnancy, respectively. Panels (b), (d), (f), (h) and (j) show cross sections of uterine horns on days $0.5,1.5,2.5,3.5$ and 4.5 of pregnancy, respectively, from animals treated with the 'minimum dose' of LPS X100.

observed in stroma without visible mitotic bodies in LPS treated animals as compared to that of the control (Figure 2c and d).

A significant decrease in the number of mitotic bodies in the luminal epithelium of uterine sections from treated animals was observed as compared to that of the control $(P<0.05)$. However, the number of mitotic bodies in glandular epithelium and stroma of uterine sections from control and treated animals did not differ significantly.

Day-2.5 of pregnancy. The cross section of uterine horns from LPS treated animals showed hyperplasic luminal epithelium with no mitotic bodies and degenerated glands with more mitotic nuclei (15 per 100 nuclei) in glandular epithelium as compared to that of the control ( $8 \pm 0.96$ per 100 nuclei) (Figure 1a and $\mathrm{b}$ ). The thickness of stroma was reduced with more mitotic bodies $(5 \pm 0.748$ per 100 nuclei) as compared to the control $(3 \pm 0.316$ per 100 nuclei) (Figure 1c). A large number of macrophages were observed in stroma and luminal epithelial layer of treated animals as compared to that of the control (Figure 2e and $\mathrm{f}$ ).

A significant decrease in number of mitotic bodies in luminal epithelium of uterine sections from LPS treated animals was observed as compared to that of the control $(P<0.05)$. A significant increase in number of mitotic bodies was observed in glandular epithelium and stroma of uterine sections from treated animals as compared to that of the control $(P<0.05)$.

Day-3.5 of pregnancy. The uterine sections from LPS treated animals showed increase in epithelial thickness and hyperplasic luminal epithelium as compared to that of the control. No mitotic bodies were observed in the luminal epithelium of cross sections of uterine horns from treated animals as compared to that of the control $(6 \pm 0.748$ mitotic figures/100 nuclei) (Figure 1a). Moreover, mitotic bodies were not observed in glandular epithelium of treated animals as compared to that of the control $(2 \pm 0.244$ per 100 nuclei) (Figure 1b). A hyperplasic glandular epithelium was observed in treated animals as compared to that of the control. A thick and oedematous stroma was observed as compared to uterine sections from treated animals on day-2.5 of pregnancy. The number of mitotic bodies was reduced ( $9 \pm 0.748$ per 100 nuclei) in stroma of treated animals as compared to that of the control $(23 \pm 1.122$ per 100 nuclei) (Figure $2 \mathrm{~g}$ and $\mathrm{h}$ ).

The number of mitotic figures in luminal epithelium, glandular epithelium and stroma of cross sections of uterine horn from the control animals were found to be significantly higher as compared to that of treated animals $(P<0.05)$.

Day-4.5 of pregnancy. The cross sections of uterus from LPS treated animals showed hyperplasic luminal and glandular epithelium. The mitotic figures were neither observed in luminal epithelium nor in glandular epithelium of the control and LPS treated animals. However, lumen closure was observed in uterine sections from the control and LPS 
treated animals. The number of mitotic nuclei was same in stroma of uterine cross sections from the control and LPS treated animals $(4 \pm 0.374 / 100$ nuclei) (Figure 1a, b and c). A larger number of leukocytes were observed in stroma of LPS treated animal as compared to that of the control (Figure $2 \mathrm{i}$ and $\mathrm{j}$ ).

A significant difference in the pattern of mitosis was observed in luminal epithelium and stroma of uterine cross sections from LPS treated animals as compared to that of the control $(P<0.001)$. Moreover, a significant modulation in the pattern of mitosis in luminal epithelium and stroma of uterine cross sections of control and LPS treated animals was observed with increase in length of gestational period $(P<0.001$, Figure $1 \mathrm{a}, \mathrm{b}$ and $\mathrm{c})$.

Effect of LPS on expression of IL-1 $\beta$ in embryos collected at different stages of preimplantation period of pregnancy

An average of $29 \pm 5$ embryos per pregnant animal were collected after superovulation. In the present study, 500 embryos recovered during different stages of the preimplantation period (i.e., days-1.5, 2.5, 3.5, $4.0,4.125,4.33, \& 4.42)$ of pregnancy from control and LPS treated animals were used at each time to study the expression of IL- $1 \beta$ by RT-PCR. The expression of $\beta$-actin gene was used as an internal standard throughout the experiments. Positive mRNA signal of IL- $1 \beta$ was observed in embryos harvested from day- 4 of gestation till implantation in control animals (Figure 3a). However, its expression was observed (from day-1.5 to 4.42 ) of pregnancy in the embryos collected from LPS treated animals (Figure 3b). A uniform expression of $\beta$-actin gene was observed in the embryos collected from control and LPS treated animals during different develop-

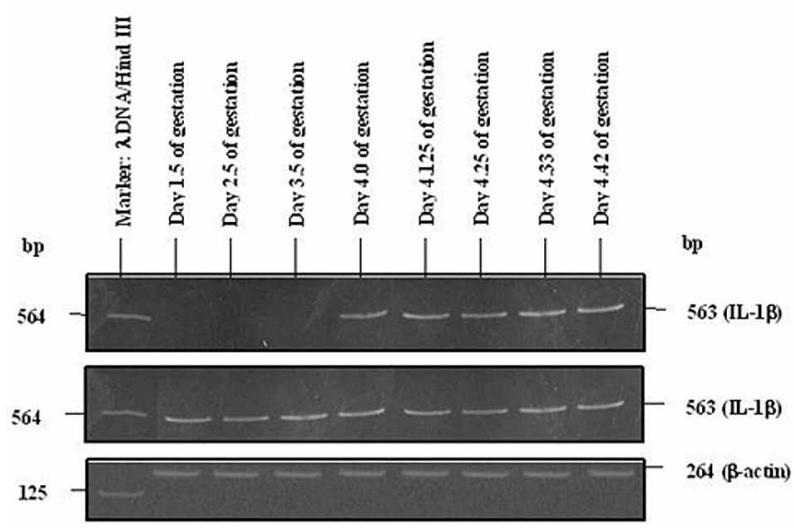

Figure 3. Detection of IL- $1 \beta$ mRNA transcripts in the preimplantation mouse embryos collected from (a) control animals, (b) animals treated with LPS at the different stages of preimplantation period of pregnancy by RT-PCR. Panel (c) shows the uniform expression of $\beta$-actin used as a positive control. mental stages of preimplantation period pregnancy (Figure 3c).

Effect of LPS on expression of IL-1 $\beta$ in uterine horns collected from different stages of preimplantation period of pregnancy

The uterine horns collected from control and LPS treated animals during different stages of preimplantation period of pregnancy (i.e., days-1.5, 2.5, 3.5, $4.0,4.125,4.33$ and 4.42 of pregnancy) were used to study the expression of the proinflammatory cytokine IL- $1 \beta$, by RT-PCR. The expression of $\beta$-actin gene was used as internal standard throughout the experiments. Positive mRNA signals for IL- $1 \beta$ were observed from day-1.5 of pregnancy till implantation in uterus collected from both the groups of animals. Its expression gradually increased from day 1.5 to 4.42 of pregnancy in uterus collected from both the groups of animals. However, it was expressed more in the uterus collected from LPS treated animals as compared to that of the control as period of pregnancy approached to stage of implantation (Figure $4 \mathrm{a}, \mathrm{b}$ ). A uniform expression of $\beta$-actin gene was obtained in the uterus collected from control and LPS treated animals during different developmental stages of pregnancy (Figure 4c).

\section{Discussion}

Endotoxins derived from Gram-negative bacteria may extensively damage preimplantation stage embryos, decrease rate of embryo cleavage, blastocyst formation and pregnancy in human [23]. The biological effects of LPS are largely mediated by the proinflammatory cytokines (e.g., IL-1, IL-6, TNF, etc.) $[24,25]$. Several cytokines have been

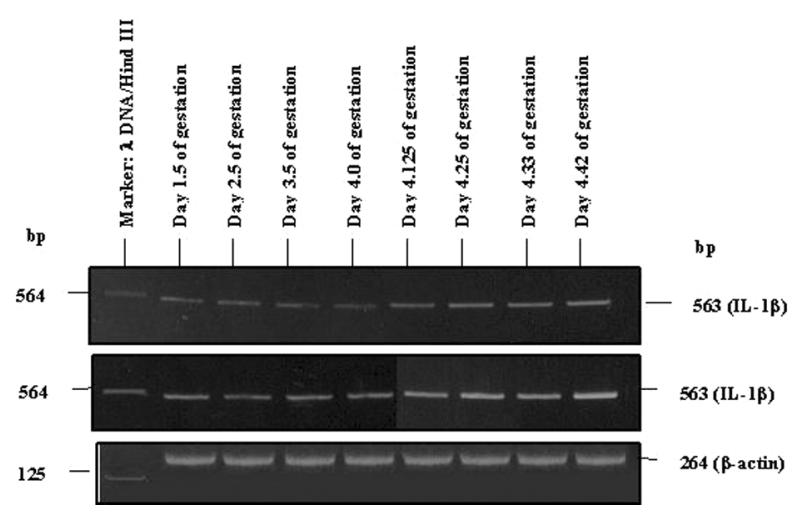

Figure 4. Detection of IL- $1 \beta$ mRNA transcripts in the uterus of (a) control animals, (b) animals treated with the 'minimum dose' of LPS at the different stages of preimplantation period of pregnancy by RT-PCR. Panel (c) shows the expression of $\beta$-actin used as a positive control. 
implicated in delicate immune system balances that exist within the feto-maternal interface [26].

The present observation about the pattern of mitosis, in the uterus of preimplantation period of pregnancy in the control pregnant animals is similar to that of an earlier report [27]. However, the number of mitotic bodies and their pattern was altered in the uterus of LPS treated animals as compared to that of the control animals (Figure 1a, b and c). We observed a proliferative switch from epithelial to stromal compartments in the uterus of control animals on day 3 of pregnancy. However, such observations are not made from the LPS treated animals and, moreover, the stroma showed a very low count of the mitotic figures. The timing of such cellular changes depends on the hormonal regimens to which the uterus is exposed. Progesterone is the primary hormone in conditioning the stromal cells to divide but in rat and mouse its further exposure to estradiol is also required [28]. A delay in stromal mitosis in response to LPS may also delay or prevent implantation and abolishes the sensitivity of the uterus to decidual stimuli in mouse [29].

The Interleukin-1 (IL-1) system (IL- $1 \alpha$, IL- $1 \beta$, and IL-1R) has previously been shown to play an important role in the development of murine preimplantation embryos [26]. IL- $1 \beta$ is expressed at the time of implantation in the embryos obtained from the control pregnant animals. Our observations on the pattern of expression of IL- $1 \beta$ in the embryos recovered from the control animals during the preimplantation period of pregnancy are supported by previous reports $[13,11]$. In a previous study, we have shown that IL- $1 \alpha$ is expressed only during the early stages of development [18]. The embryonic expressions of either of the two forms of IL- 1 through out the preimplantation period of pregnancy may be necessary to ensure a uninterrupted and upregulated expression of the $\beta_{3}$ integrins and various other genes necessary to maintain the uterus in a receptive state. The expression of secretory IL- $1 \beta$ in the preimplantation embryos recovered from control animals from day- 4 of pregnancy till implantation may be required for signaling the uterus for stromal cell proliferation and decidualization. However, LPS induced early expression of IL-1 $\beta$ (i.e., from day 1.5 of pregnancy till implantation) in the embryos may disrupt the fetomaternal signaling mechanisms required for successful implantation. The altered pattern of expression of interleukin-1 beta in the embryos in response to LPS may have autocrine and paracrine effects that may be detrimental to the embryonic development, which may alter the uterine receptivity for the implanting blastocyst and may contribute to embryonic losses in mouse.

In a previous study the expression of IL-1 receptor was not detected in the embryos of mouse at any of the stage of preimplantation period of pregnancy, however, the expression of IL-1RI was observed in the uterus of pregnant animals during this stage of pregnancy [11]. This result indicates that the embryos at the early stages of preimplantation period of pregnancy may not be capable of responding to IL-1 forms, however, it may potentially signal the maternal endometrium through the IL-1RI. The altered pattern of expression of different forms of embryonic IL-1 gene and LPS molecule itself may initiate a cascade of additional proinflammatory substances in the LPS treated animals (e.g., TNF, IL-6, and IL-8), which may contribute to infectionmediated pregnancy losses [30,31] in mice.

In the present study, we found that IL- $1 \beta$ is expressed in uterus throughout the preimplantation period of pregnancy. IL- $1 \alpha$ and IL- $1 \beta$ are produced by decidual cells in response to LPS and are present in the amniotic fluid of women with preterm labor and intraamniotic infection [32]. It has been reported that the exogeneously administered IL- $1 \alpha$ can cause fetal death and in some cases abortion in pregnant mice $[33,18]$. We observed a similarity in the pattern of expression of IL- $1 \alpha$ and IL- $1 \beta$ in the uterus of control animals.

Silver et al. (1997) [34] reported that lipopolysaccharide-induced fetal death is a prostaglandinindependent effect. Dudley et al. (1993) [35] observed that IL-1 $\beta$ and LPS significantly increases the production of $\mathrm{PGE}_{2}$ and IL-6 from murine decidua. We observed an increase in expression of IL- $1 \beta$ gene in the uterus of LPS treated animals throughout the preimplantation period of pregnancy as compared to that of the respective controls. The elevated levels of IL- $1 \beta$ may trigger the production of prostaglandins and other cytokines (e.g., TNF, IL-6, and IL-8) by the gestational tissues, leading to pregnancy loss.

The altered pattern of expression of both of the forms of IL-1 in embryos and its upregulation in uterus during the preimplantation period of pregnancy in response to LPS may stimulate the expression of COX-2 gene and the synthesis of $\mathrm{PGE}_{2}$ in the endometrial stromal and epithelial cells [36,37]. Psychoyos et al. (1973) [38] suggested that PG-mediated inflammatory reaction in the endometrium in response to the implanting embryo is necessary for implantation. Jacobs et al. (1994) [39] reported that newly differentiated luminal epithelial cells at the implantation site express COX-2. The regulation of the expression of COX2 gene is the key control of PG-synthesis and any alterations in the level of COX-2 may lead to an alteration in the biosynthesis of $\mathrm{PGE}_{2}$. Thus, a controlled expression of IL-1 in embryonic and uterine tissue may be essential for the successful implantation of embryos in mouse and any 
disturbance in the level and/or pattern of expression of this cytokine in response to LPS may lead to failure of implantation through a PG-dependent pathway.

Altered IL-1 $\beta$ expression in the preimplantation embryos and uterine horns by the 'minimum dose' of LPS may be responsible for poor embryonic development and also may cause a poor uterine preparation for implantation, by altering the expression of other developmentally important cytokines and growth factors. This might also disturb the process of decidualization as observed in our histopathological studies. Therefore, LPS induced implantation failure in mice could be due to poor embryonic development and improper preparation of the uterine horns for receiving the embryo.

\section{References}

1. Janeway CA, Travers P. Immunobiology. Oxford: Blackwell Scientific Publications Ltd; 1994.

2. Deb K, Chatturvedi MM, Jaiswal YK. Gram-negative bacterial endotoxin induced infertility: A birds eye view. Gynecol Obstet Invest 2004a;57:224-232.

3. Cram LF, Zapata MI, Toy EC, Baker B-3rd. Genitourinary infections and their association with preterm labor. Am Fam Physician 2002;65(2):241-248.

4. Deb K, Chaturvedi MM, Jaiswal YK. Comprehending the role of LPS in gram-negative bacterial vaginosis: ogling into the causes of unfulfilled child-wish. Arch Gynecol Obstet 2004b;270:133-146.

5. Dinerallo CA. Interlukin-1 and its related cytokines. Adv Immunol 1989;44:153-205.

6. Dinarello CA. Interleukin-1 and Interleukin-1 antagonism. Blood 1991;77:1627-1652.

7. Dey SK. Implantation. In: Adashi EY, Rock JA, Rosenwaks Z, editors. Reproductive endocrionology, surgery and technology. New York: Lipencott-Raven; 1996. pp 421-434.

8. Pollard JW. Regulation of polypeptide growth factor synthesis and growth factor-related gene expression in the rat and mouse uterus before and after implantation. J Reprod Fertil 1990;88:721-731.

9. Stewart CL, Kaspar P, Brunet LJ, Bhatt H, Gadi I, Kontgen F Abbondanzo SJ. Blastocyst implantation depends on maternal expression of leukemia inhibitory factor. Nature 1992;359:7679 .

10. Simon C, Piquette GN, Frances A, Danasouri IE, Zurawski G, Dang W, Polan ML. Embryonic implantation in mice is blocked by interleukin-1 receptor antagonist. Endocrinol 1994;134:521-528.

11. Takacs P, Kauma S. The expression of interleukin-1 alpha, interleukin- 1 beta, and IL-1 receptor type $1 \mathrm{mRNA}$ during preimplantation mouse development. J Reprod Immunol 1996;32(1):27-35.

12. Uehara Y, Minowa O, Mori C, Shiota K, Kuno J, Noda T, Kitamura N. Placental defect and embryonic lethality in mice lacking hepatocyte growth factor/scatter factor. Nature 1995;373:702-705.

13. Sharkey AM, Jokhi PP, King A, Loke YW, Brown KD, Smith SK. Expression of $c-k i t$ and kit ligand at the human maternofetal interface. Cytokine 1994;6:195-205.
14. Kauma S, Huff T, Krystal G, Ryan J, Takaca P, Turner T. The expression of stem cell factor and its receptor, c-kit, in human endometrium and placenta tissues during pregnancy. J Clin Endocrinol Metabol 1996;82:1261-1266.

15. Pollard JW, Bartocci A, Areci R, Oriofsky A, Ladner MB, Stanley ER. Apparent role of the macrophage growth factor CSF-1 in the placental development. Nature 1987;330:484486.

16. Guidice LC, Mark SP, Irwin JC. Paracrine actions of Insulin like growth factors and IGF binding protein-1 in non pregnant human endometrium and at the decidua-trophoblast interface. J Reprod Immunol 1998;39:133-148.

17. Hunt JS, Chen HL, Miller L. Tumor necrosis factor: Pivotal components of pregnancy? Biol Reprod 1996;54:554-562.

18. Deb K, Chaturvedi MM, Jaiswal YK. A "minimum dose" of LPS required for implantation failure: assessment of its effect on the maternal reproductive organs and IL- $1 \alpha$ expression in mouse. Reproduction 2004c;128:87-97.

19. Finn CA, Pope M, Milligam SR. Control of uterine stromal mitosis in relation to uterine sensitivity and decidualization in mice. J Reprod Fertil 1995;103:153-158.

20. Bagavandoss P, Wiggins RC, Kunkel SL, Remick DG, Keyes PL. Tumor necrosis factor production and accumulation of inflammatory cells in the corpus luteum of pseudopregnancy and pregnancy in rabbits. Biol Reprod 1990;42:367-376.

21. Chomczynski P, Sacchi N. Single-step method of RNA isolation by acid guanidium thiocyanate-phenol-chloroform extraction. Anal Biochem 1987;162:156-159.

22. Weihua Z, Saji S, Makinen S, Cheng G, Jensen EV, Warner $\mathrm{M}$, Gustafsson JA. Estrogen receptor (ER) $\beta$, a modulator of $\mathrm{ER} \alpha$ in the uterus. Proc Natl Acad Sci USA 2000;97(11): 5936-5941.

23. Dostal J, Oborna I, Talas M, Chrastinova L, Machovska K. Infectious agents and treatment of infertility with IVF and ET. Ceska Gynekol 1996;61(3):144-147.

24. Burell R. Human responses to bacterial endotoxin. Cir Shock 1994;43:137-153.

25. Keilian TL, Bleca F. CD14 and other recognition molecules for lipopolysaccharide: a review. Immunopharmacology 1995;29:187-205.

26. Kauma SW. Cytokines in implantation. J Reprod Fertil Suppl. 2000;55:31-42.

27. O'Gandy JE, Armstrong EM, Moore IAR, Vass MA. Effect of tamoxifen on mitosis in the uterus of rat during the early stages of pregnanacy. J Endocrinol 1974;63:19-21.

28. Finn CA, Martin L, Carter J. A refractory period following oestrogenic timulation of cell division in the mouse uterus. J Endocr 1969;44:121-126.

29. Heald PJ. Biochemical aspects of implantation. J Reprod Fert Suppl. 1976;25:29-52.

30. Gibbs RS, Duff P. Progress in pathogenesis and management of clinical intraamniotic infection. Am J Obstet Gynecol 1991;164:1317-1326.

31. Silver RM, Lohner WS, Daynes RA, Mitchell MD, Branch DW. Lipopolysaccharide induced fetal death: the role of TNF alpha. Biol Reprod 1994;50:1108-1112.

32. Romero R, Duram S, Dinarello CA, Oyarzun E, Hobbins JC, Mitchell MD. Interleukin-1 stimulates prostaglandin biosynthesis by human amnion. Prostaglandins 1989a;37:13-22.

33. Silen ML, Firpo A, Morgello S, Lowry SF, Francus T. Interleukin $-1 \alpha$ and tumor necrosis factor alpha cause placental injury in rats. Am J Pathol 1989;135:239-244.

34. Silver RM, Edwin SS, Umar F, Dudley DJ, Branch DW, Mitchell MD. Bacterial lipopolysaccharide mediated murine fetal death: The role of Interleukin-1. Am J Obest Gynecol 1997;176:544-549. 
35. Dudley DJ, Chen CL, Branch DW, Hammond E, Mitchell MD. A murine model of preterm labor: Inflammatory mediators regulate the production of prostaglandin $\mathrm{E}_{2}$ and Interleukin- 6 by murine decidua. Biol Reprod 1993;48:33-39.

36. Bany BM, Kennedy TG. Interleukin-1 alpha regulates prostaglandin production and cycloxygenase activity in sensitized rat endometrial stromal cells in vitro. Biol Reprod 1995;53:126-132.

37. Ishihara $\mathrm{O}$, Matsuoka $\mathrm{K}$, Kinoshita $\mathrm{K}$, Sullivan $\mathrm{MH}$, Elder MG. Interleukin -1 beta stimulated $\mathrm{PGE}_{2}$ production from early first trimester human decidual cells is inhibited by dexamethasone and progesterone. Prostaglandins 1995; 49:15-26.
38. Psychoyos A. Endocrine control of egg implantation. In: Greep RO, Astwood EJ, Geirger SR, editors. Handbook of physiology. Washington, DC: American Physiological Society; 1973. pp 187-215.

39. Jacobs AL, Hwang D, Julian J, Carson DD. Regulated expression of prostaglandin endoperoxide synthase-2 by uterine stroma. Endocrinology 1994;135:1807-1815. 


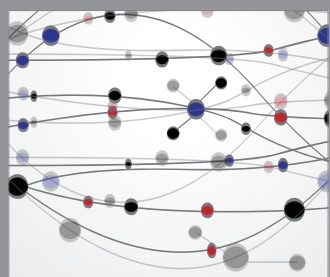

The Scientific World Journal
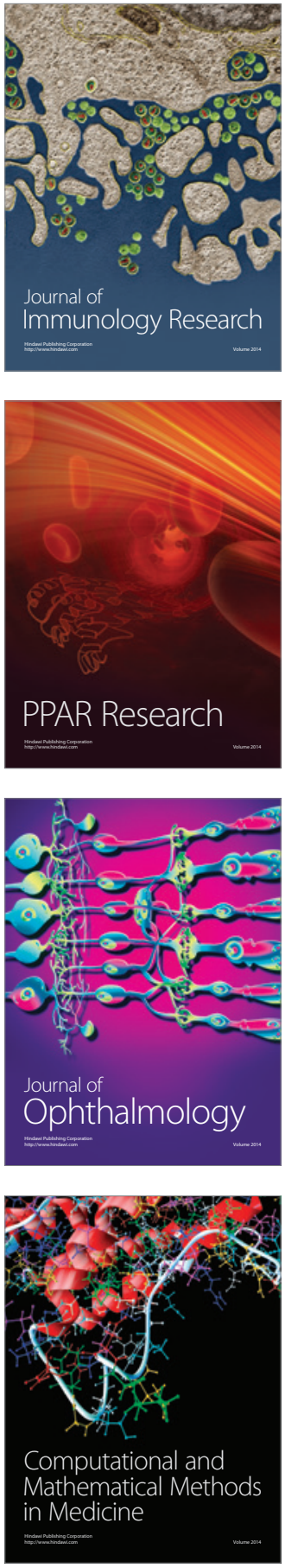

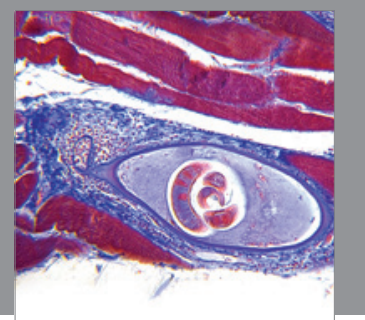

Gastroenterology

Research and Practice
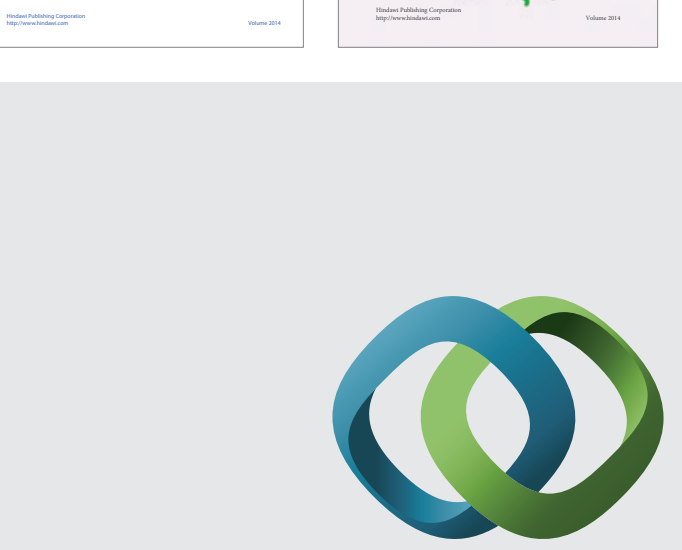

\section{Hindawi}

Submit your manuscripts at

http://www.hindawi.com
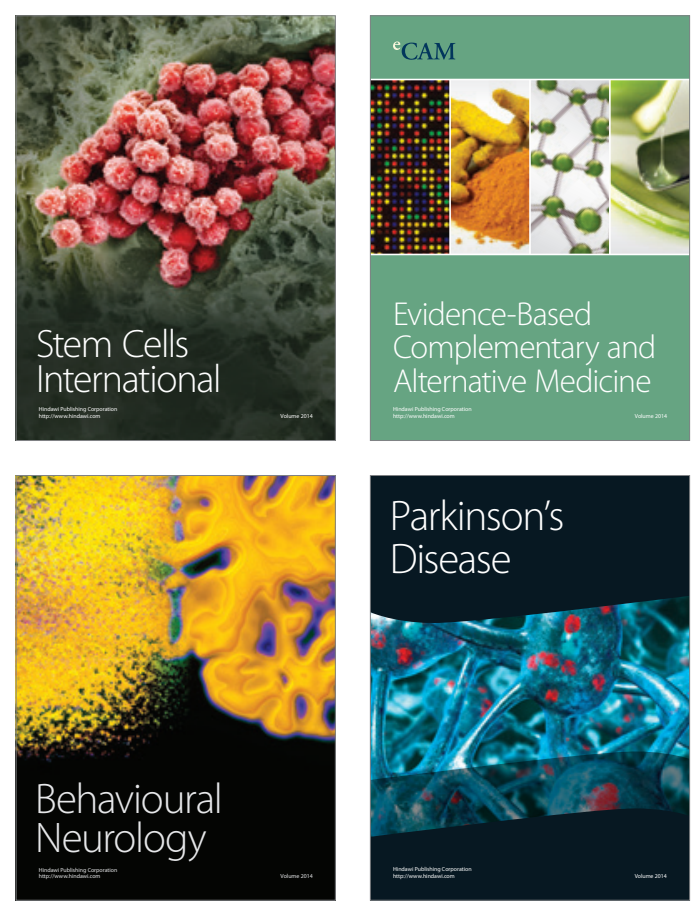

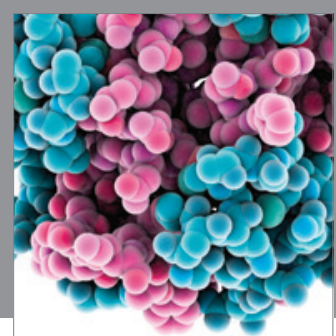

Journal of
Diabetes Research

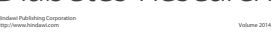

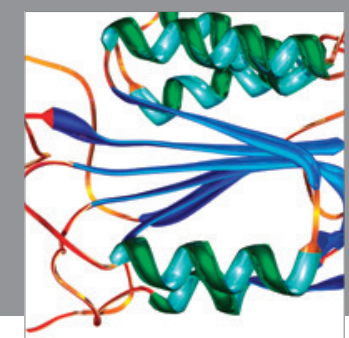

Disease Markers
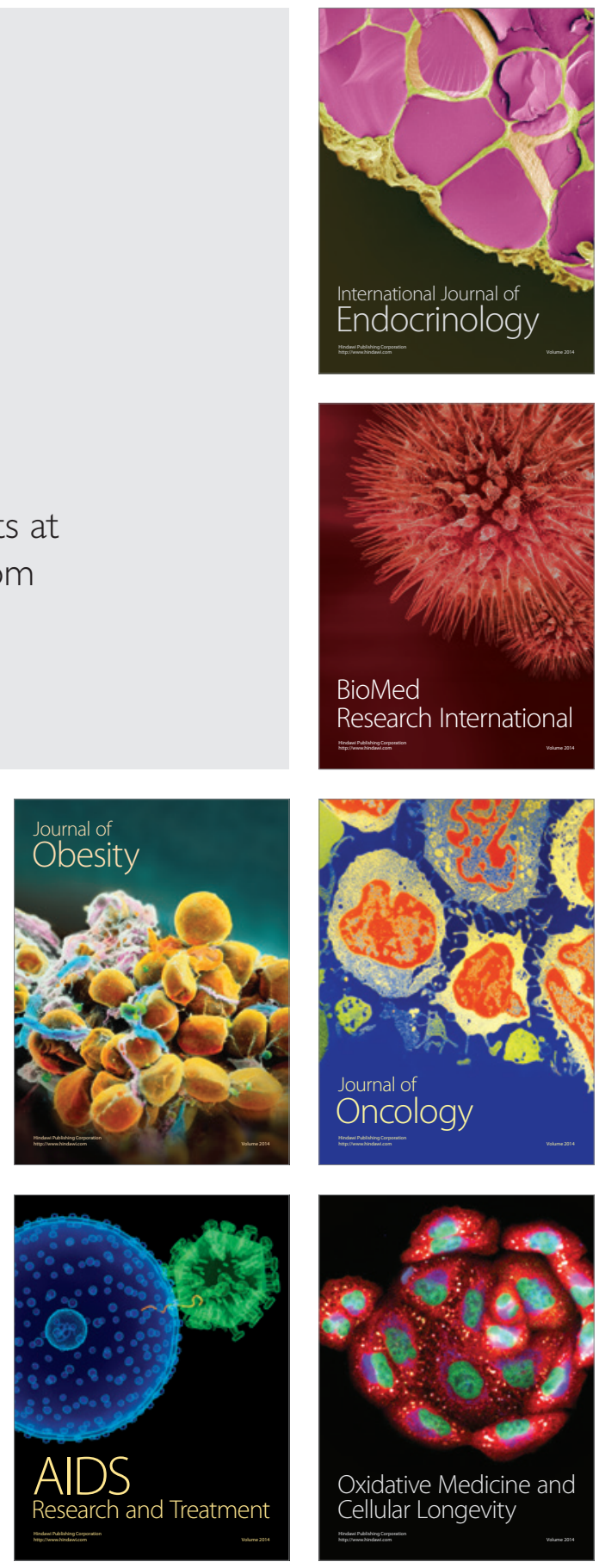